\title{
ELABORAÇÃO AUTOMÁTICA DA ESCALA DE TRABALHO DO SERVIÇO DE FARMÁCIA DE UM HOSPITAL PÚBLICO DE ENSINO DE ALTA COMPLEXIDADE DO ESTADO DE SÃO PAULO
}

\author{
Bekkers, $\mathrm{EO}^{1} \mid$ Becker, $\mathrm{AC}^{2} \mid$ Camargo, $\mathrm{PCS}^{3} \mid$ Cipriano, $\mathrm{SL}^{4}$
}

1: Dentista, aprimoranda do PROAHSA; 2: Gerontóloga aprimoranda do PROAHSA; 3: Coordenadora de Ensino do PROAHSA; 4: Diretora Técnica de Saúde do InCor

\section{INTRODUÇÃO}

De acordo com a Resolução 338 do Conselho Nacional de Saúde, a assistência farmacêutica é um conjunto de ações voltadas à promoção, proteção e recuperação da saúde individual e coletiva, tendo o medicamento como insumo essencial. Na prática, o farmacêutico realiza algumas tarefas que não estão diretamente ligadas à assistência ao paciente, uma destas é a elaboração da escala de trabalho que, nos moldes atuais, tem sido uma tarefa complexa e morosa para os profissionais responsáveis, reduzindo assim o tempo que poderia ser utilizado em prol de outras necessidades. O objetivo deste projeto foi propor um modelo viável de elaboração automática da escala de trabalho para o serviço de farmácia de um hospital público de ensino de alta complexidade do Estado de São Paulo, visando otimizar o tempo gasto na elaboração e conciliar as premissas desejadas.

\section{METODOLOGIA}

Trata-se de um estudo descritivo, realizado em novembro de 2017. O estudo buscou contemplar uma revisão bibliográfica, análise dos dados disponibilizados e benchmarking em instituições que criaram e/ou utilizam escalas automáticas, além de propostas de melhorias.

\section{RESULTADOS}

Foi realizada a descrição do modelo de escala usado na área, bem como as premissas e restrições a serem incluídas na escala automática. Em seguida, foram descritos diferentes sistemas de escala automatizadas existentes no mercado, com suas vantagens $e$ desvantagens, o que auxiliou no desenvolvimento de uma matriz de correlação usada para comparar estes sistemas. Por fim, visto que nenhum dos sistemas avaliados contempla $100 \%$ dos requisitos solicitados (Quadro 1), optou-se por desenvolver uma escala de trabalho inovadora na área de saúde, utilizando-se a ferramenta Macro do Excel. Uma macro é uma sequência de comandos e funções armazenados em um módulo de VBA (Visual Basic for Application) que automatiza tarefas repetitivas, gerando uma menor perda de tempo em etapas demoradas.

\begin{tabular}{|c|c|c|c|c|c|}
\hline \multicolumn{6}{|c|}{ Matriz de Correlação } \\
\hline & Sistema 1 & Sistema 2 & Sistema 3 & Sistema 4 & Sistema 5 \\
\hline Criação de escala automática & $\mathrm{x}$ & $\mathrm{x}$ & & & \\
\hline Dashoboard do gestor & $\mathrm{x}$ & $\mathrm{x}$ & $\mathrm{x}$ & $\mathrm{x}$ & $\mathrm{x}$ \\
\hline $\begin{array}{l}\text { Possibilidade de incluir } \\
\text { premissas }\end{array}$ & $\mathrm{X}$ & $\mathrm{X}$ & & & $\mathrm{X}$ \\
\hline Quadro mínimo preenchido & $\mathrm{x}$ & $\mathrm{x}$ & $\mathrm{x}$ & $\mathrm{x}$ & $\mathrm{x}$ \\
\hline $\begin{array}{l}\text { Trocas entre funcionários } \\
\text { supervisionada }\end{array}$ & $\mathrm{X}$ & $\mathrm{x}$ & $\mathrm{X}$ & $\mathrm{X}$ & $\mathrm{X}$ \\
\hline Cálculo de horas em haver & & $\mathrm{x}$ & & & \\
\hline Remanejamento automático & $\mathrm{x}$ & $\mathrm{x}$ & & & \\
\hline $\begin{array}{l}\text { Carga horária e locais de } \\
\text { trabalho delimitados }\end{array}$ & $\mathrm{X}$ & $\mathrm{X}$ & & & $\mathrm{X}$ \\
\hline Sistema gratuito & $\mathrm{x}$ & & & & \\
\hline $\begin{array}{l}\text { Escala única com todos os } \\
\text { funcionários }\end{array}$ & & & & & $\mathrm{X}$ \\
\hline
\end{tabular}

\section{CONCLUSÃO}

Existem alguns sistemas automatizados de escala de trabalho sendo utilizados no mercado, porém, o uso da função Macro do Excel foi a solução mais compatível com a demanda, possibilitando realizar todas as premissas solicitadas. Este método ainda é pouco conhecido na área de saúde. Conseguir automatizar esse tipo de trabalho é fundamental para que os profissionais possam utilizar seu tempo em atividades relevantes de sua competência.

\section{REFERÊNCIAS}

. BRASIL. Resolução CNS n³38 de 06 de maio de 2004. Aprova a Política Nacional de Assistência Farmacêutica. Diário Oficial da União. Brasília, mai. 2004. Disponív el em: <http://bvsms.saude.gov.br/bms/saudelegis/cns/2004/res0338_06_05_2014.htmls. Acesso em: 18 out. 2018.

2. RANGEL, A.L., ÉVORA, Y.D.M. Elaboração automática da escala periódica de trabalho dos profissionais de enfermagem por meio de um software específico. Revista Eletrônica de Enfermagem, v. 09, n. 01, p. 17 - 30, 2007. Disponível em: <http://www.fen.ufg.br/revista/v9/n1/v9n1a02.htm>. Acesso em: 08 nov. 2017.

3. POLTOSI, M.R., GÓMEZ, A.T. Elaboração de Escalas de Trabalho de Técnicos de Enfermagem com Busca Tabu e Algoritmos Genéticos. In: XXXIX Simpósio Brasileiro de Pesquisa Operacional, 2007, Fortaleza. Anais do XXXIX Simpósio Brasileiro de Pesquisa Operacional. Rio de Janeiro: SOBRAPO, 2007. p. 1832-1843.

4. DELIBERATO, R. et al., Physician satisfaction with a multi-platform digital scheduling system. Plos One, 2017. 